\title{
PAGES Data Board Meeting
}

Kandersteg, SWitzerland, 4-6 March 2002

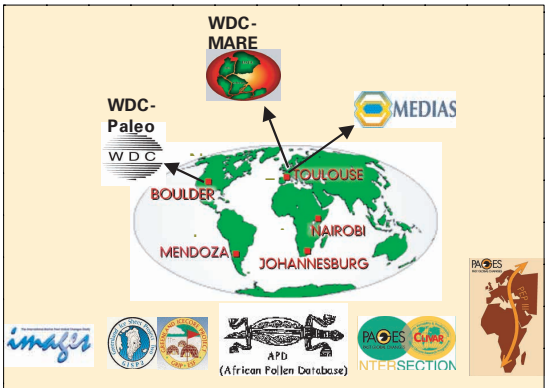

Fig. 1: Many of the data centers and data activities that are part of the PAGES Data System.

At the inaugural meeting of the new PAGES Data Board a list of planned actions and data policies was drawn up. Members in attendance at the inaugural meeting included representatives from all of the major data archives such as The World Data Center for Paleoclimatology in Boulder, USA, the World Data Center for Marine Environmental Data and PANGAEA in Germany as well as MEDIAS-France. In addition, representatives from thematic data collection efforts such as the African, European and North American Pollen databases and the IMAGES program were also present. Although participation in the workshop was necessarily limited, membership in the PAGES data board is open to all interested scientists and organizations. A full list of the proposed new PAGES Data board policies, which have subsequently been approved by the PAGES Scientific Steering Committee, is available on our web- site www.pages-igbp.org. Here we highlight a few of the major outcomes of the meeting:

Members of the PAGES Data System will work to encourage and facilitate access and exchange of paleoenvironmental data by:

- establishing networks for data management,

- providing tools to facilitate data contribution and improve data utility, and

- increasing data sharing through development of common formats for data and metadata interchange

New members are always welcome in the PAGES Data System, their management activities should:

- be developed in coordination with existing data management programs and centers (Fig. 1)

- use existing databases and systems where appropriate,

- use the metadata profiles and interchange systems approved by the PAGES Data Board for paleometadata management and exchange,

- establish a protocol to define the expected flow of data from scientists, through discipline or project based data programs, to long-term archive, and

- fully document data following established standards for metadata and data.

In the near future, members of the Data Board will cooperate to create a web based metadata portal compatible with, and linked to, the data archives maintained by all members. This portal, which will be mirrored by all the participating organizations including the PAGES IPO, will allow scientists to search for, or submit, any type of quantitative paleodata using simple keywords. This tool will allow fast and easy access to paleodata archived around the world.

The success of this initiative depends on the cooperation of various database managers, which was achieved during this first Data Board meeting, but more importantly, it depends on the willingness of individual scientists to submit their data to a participating archive. As one way to support this initiative, PAGES will request that the data used to create any figure published in a science highlights in PAGES News, be made publicity available in a participating data archive.

ISABELLE LAROCQUE

PAGES IPO, Bern Switzerland

larocque@pages.unibe.ch

\section{MARK EAKIN}

World Data Center for

Paleoclimatology, Boulder, USA

mark.eakin@noaa.gov

\section{Michael Diepenbroek}

Alfred Wegener Inst. for Polar\&Marine

Research,

Bremerhaven, Germany

mdiepenbroek@pangaea.de

\section{PAGES Meeting on High Latitude Paleoenvironments}

\section{Moscow, Russia, 16-17 MaY 2002}

Studies of environmental changes in the Arctic region are important not only for understanding vegetation and climate history inside the polar circle, but over the entire Earth. This PAGES meeting in Moscow brought together over 100 palaeoscientists working in northern Eurasia. The twoday schedule included 25 keynote lectures and more than 80 poster presentations. A wide variety of topics - from global carbon balance to climatic influences on ancient Egyptian society - covering geographical regions from the Barents Sea to the Tian-Shan Mountains and from Ukraine to Kamchatka - were covered, making it difficult to write a consistent overview. Unlike conventional meetings on High Latitude Environments, this meeting specifically sought to bring together the results obtained by the research teams of the former USSR, in collaboration with foreign partners, during the last ten years.

In the opening lecture Keith Alverson (Bern, Switzerland), provided an overview of PAGES and called for greater participation from the Russian and eastern European paleoscience communities. Eugene Vaganov (Krasnoyarsk) and Stepan Shiyatov (Ekaterinburg) presented results and perspectives from dendrochronological studies in the Urals and Siberia. These include full Holocene tree-ring chronologies and seek to reconstruct annually resolved temperature variatiability from tree-ring data. Significant shifts of the timberline in the Polar Ural Mountains was shown to 


\section{Workshop Reports}

have occurred during the historical period. The upper limit of tree growith is dated to mid-thirteenth century $A D$ and the lower to the end of nineteenth century AD. These timberline oscillations reflect changes in summer temperatures. As a further example, a 7310 year long chronology (from 5309 BC to 2000 AD) derived from more than 2700 samples of Siberian larch collected along the modern timberline in Yamal Peninsula was presented by Rashit Hantemirov (Ekaterinburg).

Lake and peat deposits were also presented as important palaeoenvironmental archives in northern Eurasia. The Baikal Drilling Program first demonstrated the possibility of reconstructing continuous records of climatic and environmental changes in eastern Siberia over the last 10 million years. Eugene Karabanov (Columbia, USA) and Elena Bezrukova (Irkutsk) debated the Pleistocene-Holocene history of the Baikal region. The Lake Baikal data show many similarities, but also significant differences, when compared with the North Atlantic records. In particular, the diatom record suggests that the Baikal ecosystem did not recover from YD glacial stress until $8.1 \mathrm{kaBP}$, long after the end of the Younger Dryas cold period in North Atlantic records, furthermore the highest diatom productivity is observed from 2.4 to $1.0 \mathrm{kaBP}$ rather than in the mid-Holocene as in the Atlantic or West Siberian records.

Qualitative pollen-based reconstruction of Holocene climate fluctuations in the Russian Arctic was discussed by Dmitry Bolshiyanov (StPetersburg). He reported spatial and temporal differences in the climate patterns reconstructed for different sectors of the Arctic, suggesting that the environmental history of northern Eurasia was rather complex and that changes in Holocene climate did not occur simultaneously over the continent. The need for highresolution data to reconstruct different aspects of late Pleistocene glaciations, including the last glacial maximum, in northern Eurasia (particularly their size and climatic effects) was stressed by Valery Astak-

A

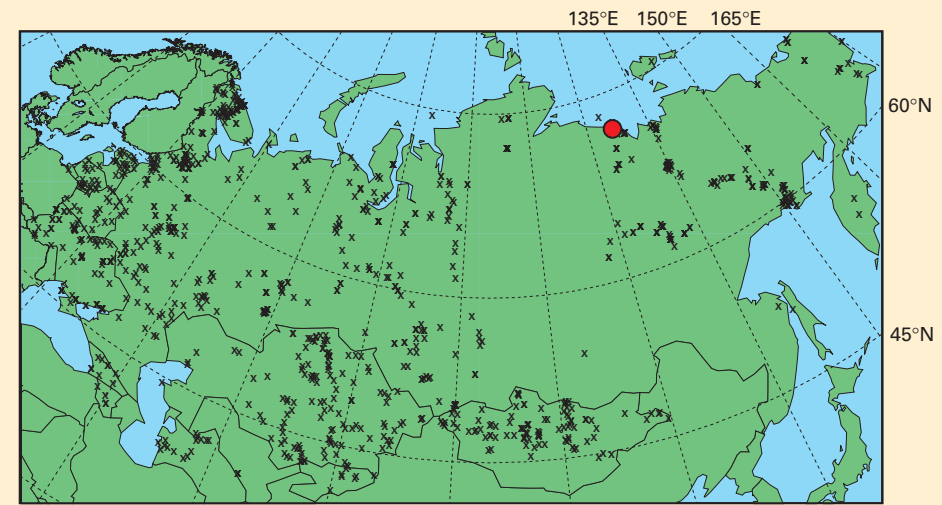

B
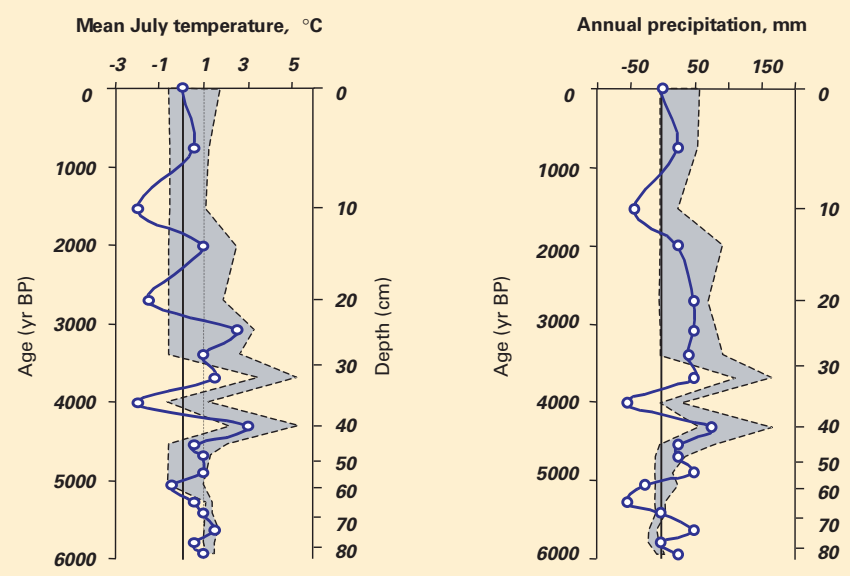

Fig. 1: A: Distribution of 1110 surface pollen samples from norhern Eurasia used as the refer ence data set to reconstruct climate from the fossil pollen record. B: Mean July temperature and annual precipitation (expressed as difference from modern climate) derived from Nikolay Lake pollen record $\left(73^{\circ} 20^{\prime} \mathrm{N}, 124^{\circ} 12^{\prime} \mathrm{E}\right.$, red dot on the map) with two statistical approaches: information-statistical method (blue line) and best modern analogue method (the range of most probable anomaly values is shown in grey, eight best analogues are considered for each fossil spectrum). From Andreev, A., Tarasov, P., Schwamborn, G. Ilyashuk, B. Ilyashuk, E., Bobrov, A., Klimanov, V., Rachold, V. and Hubberten, H.-W., submitted, High resolution Holocene paleoenvironmental records from Nikolay Lake, Arga Island, Lena River Delta, J. of Holocene.

hov (St-Petersburg) and several other speakers.

The results presented in Moscow indicated a wealth of regions in northern Eurasia, where palaeonvironmental studies have been intensively carried out over the past decade. However, for large areas of Central and Eastern Siberia and the Russian Plain as well as Middle Asia and Kazakhstan, we still need more high-resolution records in order to precisely reconstruct the timing and nature of Late Quaternary environmental variability in these regions (see e.g., Fig.1).Though the area of the former Soviet Union is no longer terra incognita for the international palaeoenvironmental community, significant gaps in understanding, such as the limits of the LGM glaciation and early to midHolocene monsoon-like circulation, still exist. Oksana Savoskul and
Pavel Tarasov (Moscow) pointed out that a future strategy for obtaining new, high-resolution data should be combined with the collection and critical evaluation of existing palaeoenvironmental records published in Russian papers and reports. In part towards this end, the meeting chair, Olga Solomina together with Keith Alverson at the PAGES IPO, are planning on editing a special issue for publication in an English language peer reviewed journal with contributions from various participants at the conference. Interested scientists are encouraged to contact one of the editors for further information.

\section{Pavel E. Tarasov}

Geography Department, Moscow State University, Russia paveltarasov@hotmail.com 